\title{
MULHER E HISTORIOGRAFIA: DA VISIBILIDADE À DIFERENÇA *
}

Maria de Fátima da Cunha "

Resumo: Este artigo tem como objetivo traçar um balanço da historiografia que aborda a temática feminina, em suas várias vertentes: do marxismo, passando pela história social até os estudos de gênero, em um período que vai dos anos 70 até os anos 90 , no Brasil.

Unitermos: historiografia, mulheres, gênero.

\section{O Resgate do Feminino:}

Assim que os debates sobre a família e principalmente sobre a mulher ganham uma importância mais significativa, emerge uma historiografia que traz à tona a imagem da mulher reconstruída a partir da ótica que a via presa a um tipo de representação: ser despossuído de identidade, reflexo do homem

Segundo essa abordagem, através dessa tradição narrativa, a mulher era percebida como tentadora do homem, aquela que perturbava a sua relação com a transcendência e também aquela que conflituava as relações dos homens entre

\footnotetext{
"Este artigo, elaborado a partir de leituras realizadas para o desenvolvimento de nossa tese de doutorado, ainda em andamento, realiza um breve balanço da historiografia que aborda o feminino e questões de gênero, especialmente durante os anos 80 e 90 , no Brasil.

" Professora do Departamento de História da Universidade Estadual de Londrina e doutoranda pela UNICAMP.
} 
si. Assim, nessa perspectiva, a mulher passa, então, a ser intimamente ligada à idéia da natureza, à carne, ao sexo, ao prazer, domínios que tinham de ser rigorosamente normatizados. (MURARO,1991:10).

Com esta intenção, a serpente, símbolo ligado à fertilidade nas eras matriarcais e considerada expressão máxima da sabedoria, passava a ser identificada com o demônio, com a luxúria. Neste sentido, colocava-se o sexo como pecado supremo e, conseqüentemente, o poder ficava imune a críticas ${ }^{1}$.

Desse modo, para essa abordagem interpretativa, ocorre que, de doadora da vida, imagem própria da fertilidade para as colheitas e os animais, a mulher, numa completa inversão, passava a ser considerada a primeira e a maior pecadora, a origem de todas as ações nocivas ao homem, à natureza e aos animais. Força do mal, potência noturna, oposta ao homem diurno, representante da ordem e da razão lúcida.

Portanto, relegada a um segundo plano na história, não era de se admirar que durante muito tempo a produção historiográfica dessa à mulher um espaço pouco representativo em suas abordagens.

A partir da expansão da Nouvelle Histoire e da Antropologia Histórica é que se iniciou uma ampliação do debate sobre a família e a sexualidade. Especialmente com a História das Mentalidades, com preocupações voltadas sobre o popular, é possível vislumbrarmos uma abertura para a história da mulher. (DEL PRORI, 1989).

Segundo a análise de Mary del Priore, duas características marcaram o início das produções sobre o feminino: fazer emergir a mulher no cenário de uma história pouco preocupada com as diferenças sexuais e demonstrar a exploração, a opressão e a dominação que a vitimava.

\footnotetext{
1 Rose Marie Muraro ressalta que apenas nos tempos modernos tentou-se deslocar o pecado da sexualidade para o poder. Até hoje, em sua opinião, não só o homem como as classes dominantes tiveram seus status sacralizados porque a mulher e a sensualidade foram penalizados como causa máxima da degradação humana. Idem, p. 10.
} 
Para essa autora, trabalhos marcados por esses direcionamentos acabavam levando a história da mulher a um isolamento intelectual e a estudos sem maiores influências na disciplina histórica. Na sua ótica, deve-se fugir da história que faz da mulher uma vítima, ou o seu inverso, idéia corroborada por esse estudo.

Especialmente no Brasil, através da historiografia que analisa a temática feminina, pode-se verificar que são resgatados vários aspectos da condição feminina, em períodos que variam do século $\mathrm{XIX}$ até meados do século $\mathrm{XX}$, como: ama-de-leite, operária, prostituta, militante, solteirona, entre outros. ${ }^{2}$

A maioria desses estudos coloca em discussão a imagem que se tinha da mulher até o século XIX, quando esta era identificada -e identificava-se- como "pária" da sociedade, condição que serviu para construir a imagem da "diferença" e da "exclusão", constitutiva da consciência-identidade feminina neste século.

Tal imagem começa a ser definitivamente recusada pela mulher a partir da segunda metade do século passado. Também é rejeitado o destino social de permanecer confinada no âmbito das atividades domésticas, exercendo unicamente as funções de mãe e esposa, só assim adquirindo status, através do casamento.

Falando da condição feminina e da visão da mulher como "ser socialmente" destinado à reprodução da espécie e "incapaz" de atingir a plena racionalidade -atributo

2 Cabe ressaltar que os estudos pioneiros sobre a mulher no Brasil incidiram, em especial, sobre a sua condição no século XIX. Nesse período, a mulher foi objeto de várias análises, realizadas através de literatura de viagem, aprofundando o conhecimento dos papéis históricos, principalmente das classes oprimidas: livres, escravas, e forras. Entre esses trabalhos destacam-se LEITE, Miriam L. Moreira A condição Feminina no Rio de Janeiro, Séc. XIX - Pró-memória -INL - SP/Brasília - 1984 ; DIAS, Maria Odila - Quotidiano e Poder em São Paulo no Século XIX - SP - Brasiliense - 1984 e SILVA, Maria Beatriz N. - Sistema de Casamentos no Brasil Colonial - SP - T. A . Queiroz e Edusp - 1984. 
essencialmente masculino-, Maria Stela Bresciani argumenta que o privilégio da participação e da "plenitude racional" foram sempre exercidos por uma reduzida parcela de homens: os proprietários. Aos não proprietários, mulheres e escravos, restavam o anonimato e a labuta dos afazeres domésticos. ${ }^{3}$

Assim, Bresciani atenta para o fato de que a história da mulher enquanto cidadã é, ao mesmo tempo, uma "história da exclusão" e a "história de uma luta", principalmente para ser reconhecida -e para se reconhecer- como indivíduo capaz de dominar os princípios da ética e da racionalidade da vida pública. ${ }^{4}$

A visão que aponta a impossibilidade do domínio da razão pela mulher fundamenta-se, como informa Michele Perrot, na teoria e estereótipo elaborados no século XIX, baseados no discurso naturalista, que insistia na existência de duas "espécies" com qualidades e aptidões diferenciadas. Aos homens o cérebro -mais importante que o falo-, símbolo da razão lúcida, da capacidade de decisão. Às mulheres, o coração, a sensibilidade, os sentimentos. ${ }^{5}$

Com relação à atenção dispensada pela narrativa histórica tradicional ao tema da mulher, Perrot ao avaliar a memória que o investiga, bem como as fontes disponíveis para esse estudo, localiza uma quase ausência da história da mulher. Para a autora, tal evidência se revela porque essa narrativa privilegia em demasia

${ }^{3}$ Cf. Revista Brasileira de História - A Mulher e Espaço Público - n. 18 - ANPUH/ Marco Zero - 89/90.

4 Nesta mesma direção Hannah Arendt considera que "desde os primórdios da História" a parte corporal da existência humana, tudo que era ligado à necessidade do processo vital, precisou ser escondido, ocultado. Assim, os trabalhadores, "que com seu corpo cuidavam das necessidades (físicas) da vida", e as mulheres, que igualmente com seu corpo, "garantiam a sobrevivência da espécie" eram segregados da comunidade. Para Arendt, é sintomático que ambos - mulheres e trabalhadores - tenham sido "emancipados" no mesmo momento histórico, quando as funções corporais e os interesses materiais já não precisavam mais ser escondidos. Cf. ARENDT, Hannah - a Condição Humana - RJ - Forense Universitária - 1991 - p. 83.

${ }^{5}$ Conferir essas considerações de Maria Stela Bresciani feitas na apresentação da Revista Brasileira de História, no. 18. 
a cena pública, em especial a política e a guerra, locus reservado ao homem, por excelência. (PERROT, 1988: 177).

Esse espaço se reduz ainda mais quando se verifica que os arquivos públicos, organizados por homens, realizam uma seleção que deixa poucos registros sobre o feminino. Quando trazidas à cena, geralmente as mulheres aparecem através de estereótipos amplamente veiculados: vociferantes quando falam e histéricas quando gesticulam. Tal visão aponta para o fato de que raramente elas são consideradas por si mesmas, com freqüência são vistas como sintoma de "febre" ou "abatimento". (PERROT, 1989-90).

Sobre as mulheres do povo, o silêncio é ainda maior, e só se fala delas quando suas insatisfações com o preço do pão, por exemplo, começam a preocupar, ou quando provocam brigas contra os comerciantes e proprietários, ameaçando subverter a ordem através da greve.

Assim, na ótica de M. Perrot, os arquivos públicos, "olhar de homens, sobre homens, calavam as mulheres". Um outro caminho para os pesquisadores, apontado por ela, seria o dos arquivos privados, nos quais as mulheres se exprimiam de maneira mais abundante, pois as correspondências e os diários íntimos eram recomendados às jovens solteiras por seus confessores e pedagogos, como forma de controle sobre si, transformando-se num domínio de refúgio para elas.

Restaria ao pesquisador a sorte de encontrar tais arquivos intactos, posto que a queima dos diários pelas mulheres, para ocultar suas vidas pessoais, era muito comum, atestando, por sua vez, a adesão ao silêncio que a sociedade lhes impunha.

Entretanto, é possível verificar que, em alguns momentos, as mulheres conseguem ultrapassar os limites do espaço privado destinado a elas. Essa superação é quase sempre feita pela via da excepcionalidade: da notoriedade pelo sucesso de suas profissões, pela militância política ou pelo casamento. Em outros casos o destaque é alcançado pelo trágico caminho da criminalidade, da prostituição e até mesmo da loucura.(BRESCIANI, 1989-90). 
É bom lembrar que a representação simbólica da mulher, enquanto esposa-mãe-dona-de-casa, afetiva mas assexuada, é forjada por caminhos sofisticados, embora o momento de crescente urbanização e desenvolvimento comercial e industrial solicitasse a presença das mulheres nas ruas e exigisse a sua participação ativa no mundo do trabalho.(RAGO, 1985:62).

Analisando, nas décadas iniciais do século $X X$, a preocupação de médicos-higienistas, autoridades públicas e setores da burguesia em formar uma nova figura do trabalhador e de sua família, integrando-os no universo de valores burgueses, Margareth Rago percebe a elaboração de um novo modelo de feminilidade. A mulher cabia, agora, atentar para os ínfimos detalhes da vida cotidiana de cada um dos membros da família, vigiar seus horários, estar a par de todos os pequenos fatos do dia-a-dia, prevenir a emergência de qualquer sinal de doença ou de desvio.

Por outro lado, ainda na ótica de Rago, o movimento operário, liderado por homens, atua no sentido de fortalecer a intenção disciplinadora de deslocamento da mulher da esfera pública do trabalho e da vida social para o espaço privado do lar, obstaculizando sua participação nas entidades de classe, nos sindicatos e no próprio espaço de produção, reproduzindo, desta forma, a exigência burguesa de um novo ideal feminino para a mulher, consagrado ao lar e à maternidade.

Essas propostas de ordenação social em que a mulher é incumbida da missão de "guardiã do futuro", são investigadas também por Maria Cândida D. Reis ao estudar o tema Mulher e Educação, em São Paulo, nas três primeiras décadas deste século. Através deste trabalho, podemos verificar que além do papel de esposa e mãe, destinava-se um outro à mulher: o de mestra.

A autora evidencia, igualmente, os encaminhamentos dados para a educação do sexo feminino, que visava, sobretudo, à disciplinarização do corpo. Não obstante, através de sua obra, é possível observar os "fios soltos dessa trama", quando traz à 
luz as vozes dissonantes de mulheres como Maria Lacerda Moura e Patrícia Galvão, rebeldes por razões diferentes, que ousam contestar o sistema educacional disciplinador do período. (REIS, 1993).

Cabe frisar também que as idéias veiculadas, no início do século, pela Medicina Social e higienista sobre a mulher frágil e submissa são rompidas, na prática, por algumas mulheres.

Rachel Soihet, estudando processos criminais no Rio de Janeiro, demonstra que o comportamento feminino diferia, em diversas situações, daquele veiculado pela ideologia dominante. Algumas mulheres -ousadas e apaixonadas- não conseguindo manter o controle sobre as suas paixões, rompendo com determinados padrões que lhes eram atribuídos, fugindo à docilidade alegada ao sexo feminino, violando deste modo, os preconceitos, os costumes e as leis sociais da época, através dos crimes passionais, acabavam incorrendo na "vergonha" e no "crime". E, como lembra a autora, teriam que pagar caro por isso. (SOIHET, 1989-90: 199-216).

Para a mulher deste período, recusar o casamento, a maternidade, a família e manifestar independência, era uma atitude essencialmente estranha àquela sociedade. A transgressão pela mulher do papel que lhe era destinado não significava, aos olhos da Medicina Social, apenas um rompimento das normas sociais, mas sim uma violação da própria natureza. Ou seja, significava "loucura".

$E$, neste sentido, para Maria Clementina P. Cunha, a psiquiatria alienista que emerge no final do século XIX, procura sancionar e condenar mulheres que assumem comportamentos considerados "estranhos". Ao julgamento do que era "estranho", atrelava-se logo a idéia da manifestação da loucura, que se revelava através da "histeria", e que tinha como traços principais:"...a fraqueza de vontade, hipersensibilidade e emotividade, (...) leviandade, sugestibilidade e (...) desvio na função sexual..." (Grifos Meus). (CUNHA, 1986: 146).

É possível perceber que a adequação da função sexual 
da mulher -destinada à procriação e não ao prazer - aparece como problema crucial para a classificação das mulheres como loucas. E, nesta ótica, diversas são internadas por "exageros" no comportamento sexual (coquetterie doentia) ou por frigidez e anestesia sexual, especialmente as mulheres casadas.

Quanto às mulheres trabalhadoras, há muito existia uma expectativa -veiculada por setores marxistas- de que elas se libertariam da opressão quando, juntas com os homens, na condição de trabalhadoras assalariadas (ou seja, enquanto classe), rompessem suas amarras ao se incorporarem ao mercado de trabalho, experimentando as contradições entre capital e trabalho. Tal expectativa, no entanto, não se efetivou. Muito pelo contrário: a exploração feminina ampliou-se ainda mais.

Para Maria Valéria Junho Pena, à exploração da mulher, enquanto classe, se adicionou sua sujeição enquanto mulher. Pois o mesmo capitalismo que as assalariou não permitiu que sua identidade ligada ao trabalho doméstico se quebrasse. Portanto, na perspectiva capitalista, as mulheres seriam duplamente úteis, como trabalhadoras e como mães/esposas: pelo seu trabalho na produção e pelo seu trabalho na reprodução; criando valores de troca e criando trabalhadores/as.

Desse modo, para essa pesquisadora, a sujeição/ opressão da mulher trabalhadora está intimamente ligada ao funcionamento de dois sistemas que se interligam: o capitalismo e o patriarcalismo. (PENA, 1981: 15,57).

No entanto, há que se ressaltar que nas, últimas décadas, a abordagem da temática da mulher avançou para além das articulações entre capitalismo e patriarcalismo, encaminhandose para uma crítica à própria abordagem marxista da mulher $\mathrm{e}$ da sexualidade.

Nessa perspectiva, caberia uma indagação sobre o tratamento dispensado pela esquerda, em especial pelo marxismo, à temática da mulher. 


\section{Thompson, Scott e o gênero:}

As análises sobre a opressão das mulheres, feitas pela esquerda -no final do século XIX e início do XX-foram sempre muito limitadas, restringindo-se a considerações que enfatizavam a exploração de classes da sociedade capitalista, que deixaria de existir no socialismo. Como salientam Elizabeth S. Lobo e Maria Celia Paoli, as operárias feministas além de denunciar as condições de exploração da força feminina de trabalho, os baixos salários e a opressão sexista exercida pelos patrões, lutaram, igualmente, contra os próprios sindicatos que discriminavam as mulheres e contra a tirania que as vitimava também no interior da família operária.

A maioria dessas denúncias foram silenciadas em nome da tese que via a situação opressiva da mulher como produto da sociedade e que, por conseguinte, como já havíamos indicado, o seu fim dar-se-ia através da revolução socialista. (LOBO\&PAOLI, 1982: 46-57).

Assim, principalmente nos anos 70 , a produção historiográfica tomando como ponto de partida uma referência teórico-metodológica assentada nas premissas epistemológicas da história social, fortemente influenciadas pelo marxismo, preocupou-se em identificar os signos da opressão capitalista sobre elas.

Nesses anos, o movimento feminista, que estava sendo organizado nos Estados Unidos e na Europa, começa a repercutir no Brasil. Iniciam-se as primeiras publicações de livros feministas. Vários meios de comunicação como o rádio, imprensa e a televisão passam a abrir espaço para a questão feminina. A principal luta feminista consistia na recusa da divisão tradicional dos papéis sociais, bem como a visão que apontava a mulher como o "segundo sexo" ou o "sexo frágil". As feministas reivindicavam também a condição de sujeito de seu próprio corpo, da sua sexualidade e de sua vida, buscando um espaço de atuação política. 
Naquele momento, a difusão da psicanálise contribuiu de forma contundente para a rejeição de práticas que eram percebidas como autoritárias e repressivas e para o questionamento da obrigatoriedade de exercer a sexualidade dentro dos limites do casamento legítimo. A mudança social fundamental era a reivindicação de igualdade na esfera pública e privada bem como a recusa de morais sexuais diferentes para homens e mulheres. (GOLDENBERG, 1996).

Ao longo da década de 80 , emerge o que se poderia identificar como uma segunda vertente das produções acadêmicas sobre as mulheres, trazendo à tona um conjunto de estudos preocupados em revelar a presença das mulheres atuando na vida social, reiventando suas práticas cotidianas criando estratégias informais de sobrevivência, construindo formas diferenciadas de resistência à dominação masculina e classista, enfatizando a sua capacidade de luta fortemente influenciados pelas análises do historiador inglês $E$. P. Thompson. (RAGO, 1994).

Vale ressaltar que as análises thompsonianas, que acabam influenciando os estudos sobre as mulheres, nascem no bojo de uma discussão muito mais ampla, no repensar do próprio marxismo. Assim, caberia indagarmos sobre o tratamento dispensado pela esquerda, em especial pelo marxismo, à temática da mulher.

As análises sobre a opressão das mulheres, feitas pela esquerda -no final do século XIX e início do século XX-foram quase sempre muito limitadas, restringindo-se a considerações que enfatizavam a exploração de classes da sociedade capitalista, que deixaria de existir no socialismo. (LOBO\&PAOLI, 1982).

$\mathrm{Na}$ verdade, sempre havia existido uma "mal-estar" na relação entre o feminismo e o marxismo. Quase sempre permanecia certos entraves de ordem teórica e política quando se tentava incorporar a chamada "questão feminina" pelo marxismo. Ao recuarmos até os movimentos socialistas do 
século XIX quando o debate político do projeto socialista tentava integrar discussões sobre os direitos das mulheres e as desigualdades entre os sexos, percebe-se que apesar da insistência por parte das mulheres comunistas no caráter social e político das desigualdades de gênero, elas tinham que se contentar com o caráter secundário dado a estas questões frente à prioridade da luta de classes. (MARTINS, 1996).

Dessa forma, para Ana Paula V. Martins, para incorporar as discussões sobre desigualdades sociais no âmbito do debate teórico marxista, as feministas procuravam explicar a questão da opressão e da submissão das mulheres a partir do paradigma da produção, procurando incluir as questões das relações sociais que envolviam a procriação, o cuidado dos filhos e 0 trabalho doméstico. Entretanto, estas formulações continuavam articulando as atividades intersubjetivas a partir do conceito de produção e, assim, as questões pertinentes às relações de sexo continuavam em segundo plano.

Neste sentido, vale lembrar a crítica de Thompson às feministas, quando afirma que apesar destas procurarem a inclusão do tema do feminino nas análises historiográficas, reduzem-no a um "pseudoproblema", tentando inseri-lo numa máquina planejada para a sua exclusão. Ao tentarem introduzilo no "planetário" elas são induzidas a desmantelar todo o caráter de desafio e identidade de seu objeto, sujeitando-o à mesma "praga geral" -entenda-se aqui a crítica de Thompson à busca de certos historiadores de um mecanismo que ligasse a base e a superestrutura. (THOMPSON, 1981).

Vale ressaltar que a intenção política da história da opressão feminina era criar uma identidade para as mulheres a partir do corpo teórico marxista. E, assim, o que unia as mulheres era a história de exploração e opressão pela ordem patriarcal e pela ordem capitalista.

Todavia, apesar do esforço intelectual e a qualidade dos trabalhos realizados sob esta ótica, a história da opressão gerou alguns equívocos como a idéia de que a escrita da história só 
deveria ser realizada pelas próprias mulheres. Essa concepção de história feita a partir da condição de oprimida, pôde ser adjetivada como linear, o que reforçava a ação masculina e a submissão feminina ao transformar a opressão no fator principal e unificador da história das mulheres. (MARTINS, 1996).

É nesse contexto que o trabalho de E. P. Thompson teve um importante significado para as historiadoras feministas, particularmente o livro sobre a formação da classe operária inglesa. Ao afirmar que procurava resgatar as práticas e experiências dos indivíduos da condescendência da posteridade, Thompson abria caminhos para a escrita de uma história que atentava para sujeitos sociais que até então só eram tidos como agentes coletivos, ou mesmo inexistentes.

A sua obra, como também de outros historiadores ingleses, como Eric Hobsbawn e Christopher Hill propunha uma outra perspectiva de análise histórica das relações sociais: a história vista de baixo. Esta perspectiva tinha como objetivo entender as relações entre as classes sociais a partir das classes baixas - camponeses e operários - sem perder de vista a natureza política dessa relações. Desta forma, como enfatiza Ana Paula Martins, o enfoque dicotômico da opressãosubordinação era deslocado para as relações de opressão, exploração, submissão, acomodação, luta e resistência. Tornavam-se, portanto, muito mais complexas as relações de poder, rompendo com os pares opostos opressor-oprimido, ao pensar os sujeitos da história enquanto sujeitos políticos.

Esta abordagem que permitia focar as relações sociais a partir de uma perspectiva político-cultural foi muito bem recebida pela história das mulheres. Era possível, então, resgatar a ação e a palavra das mulheres, que fornecesse provas não somente da opressão mas das estratégias de luta e resistência para sobreviver aos sistemas opressores.

É através da inspiração norteadora de E. P. Thompson, que se iniciam as reflexões sobre o caráter político das relações de classe, produzidas pela história social das mulheres nos anos 
80 , com ênfase no trabalho feminino e na participação política das mulheres nas sociedades em processo de transformação da ordem pré-capitalista para ordem capitalista e, igualmente, de uma cultura rural para uma cultura urbana. Segundo Ana Paula Martins, foram as historiadoras marxistas que resgataram a documentação sobre operárias e sua participação na constituição da classe operária, bem como problematizaram as transformações de ordem econômica e ideológica que sustentaram a oposição entre o público e o privado, resultando em importantes análises sobre a ideologia da domesticidade e o impacto dos valores da classe média sobre a classe operária ao longo do século XIX e início do século XX.

Desta forma, pode-se afirmar que é inegável a contribuição de E. P. Thompson sobre a historiografia, principalmente na década de 80 , ao dimensionar politicamente a formação da classe através das experiências dos seus sujeitos históricos, permitindo às historiadoras feministas problematizar o caráter genérico da classe.

Podemos dizer que se na década de 70 a história das mulheres nasce no interior de uma história do trabalho, na década seguinte é ampliado de forma intensa o leque temático não apenas me relação à incorporação de novos agentes sociais, entre estes as mulheres, mas também outras dimensões da vida social são privilegiadas. E, nesse contexto, a história das mulheres passa a adquirir um estatuto próprio, afirmando-se como área de interesse na academia.(RAGO, 1994).

Entretanto, as historiadoras do feministas não permanecem só na influência thompsoniana, mas passam também a pensar as relações sociais fundadas a partir das diferenças de gênero. É a partir desse momento que começam a surgir críticas aos conceitos utilizados por Thompson, principalmente às suas formulações a respeito de classe e experiência. Entretanto, o que se pode dizer é que tais críticas se aplicam muito mais aos seus textos mais antigos, não acontecendo o mesmo com seus debates posteriores. Essa constatação pode ser percebida em Customs in Common. 
Grande parte das críticas vieram das próprias historiadoras influenciadas pelo trabalho de Thompson. Em especial, criticava-se a ausência de uma explicação sobre o significado político e cultural das mulheres no processo de formação da classe. Ou seja, para essas pesquisadoras, era possível se falar que tal concepção era neutra ou possuía uma visão masculina da história da identidade de classe. Para Catherine Hall, isso acontecia porque o conceito de experiência de Thompson não dava conta das diferenças.(HALL,1988). As críticas mais contundentes ao trabalho do historiador inglês, foram realizadas por Joan Scott. Para ela, o conceito de classe deveria explicar as diferentes experiências de homens e mulheres nas relações de produção, ampliando, assim, o conceito de classe, ao abordar as descontinuidades, as representações e as relações de poder no interior da própria classe.(SCOTT, 1990: 5-22).

Entretanto, vale dizer que à medida em que avançam os estudos de Thompson sobre a cultura plebéia ele acaba incorporando em suas análises questões que se preocupam com o que se poderia chamar de "problemas de gênero". Isto pode ser percebido no artigo sobre a economia moral, de 1971 , quando o autor analisa o papel das mulheres no interior da comunidade plebéia pré-industrial e sua participação nos chamados motins de resistência. (THOMPSON, 1993).

Todavia, é no artigo sobre a venda das esposas que o historiador inglês coloca abaixo as várias interpretações de folcloristas e feministas, sobre um costume percebido por estes como um sinônimo da histórica opressão das mulheres na Inglaterra. Thompson reinterpreta o ritual da venda das esposas concluindo que o mesmo era a forma como os homens e mulheres, daquela época, se articulavam para resolver seus desamores e descasamentos. Desta forma, acaba por demonstrar em sua análise a especificidade das relações de gênero, contidas em uma prática da cultura plebéia inglesa do século XVIII. Assim, como aponta Ana Paula V. Martins, é 
possível perceber interesses opostos e relações de poder diferenciadas no interior de uma mesma cultura, questões estas amplamente reclamadas pelas historiadoras feministas em seus estudos sobre a formação de classe operária.

Podemos demarcar a década de 80 , no Brasil, como o momento em que acontece uma inovação nos estudos sobre o feminino, através da utilização do gênero como categoria de análise, que procura incorporar o estudo do relacional entre homens e mulheres. Estudos realizados a partir dessa perspectiva passam a fazer uma crítica à mulher como "redentora" ou como "sujeito da revolução", descobrindo diferenciadas lutas e múltiplos sujeitos na história das mulheres.

A categoria analítica gênero tem por objetivo inverter a desconstrução da generalização "mulheres", que remetia a uma identidade social branca e de classe média, para se pensar as diferenças sexuais enquanto construções sociais e culturais. (RAGO, 1994).

A fim de melhor esclarecimento, creio que seja necessário definir de forma mais clara o que se concebe atualmente como gênero. Recorrentemente, o conceito de gênero é utilizado para desnaturalizar papéis e identidades atribuídas ao homem e à mulher. Diferencia-se também sexo (a dimensão biológica) de gênero (uma escolha cultural, um produto construído social e historicamente).

Também deve ficar claro que não se deve pensar gênero como uma categoria isenta de limites e conflitos. Nem mesmo existe um consenso em relação ao seu uso e às suas concepções.(VARIKAS, 1994: 63-84)

Para alguns pesquisadores, talvez signifique mais uma demarcação das tentativas atuais por um aprofundamento epistemológico e pela construção de novos projetos políticos que redimensionam as relações de gênero na academia e fora dela. (BESSA, 1994: 175-196).

A pesquisadora Joan Scott, a fim de uma maior compreensão do uso do gênero, define-o como portador de duas 
partes, e várias subdivisões, interligadas mas analiticamente distintas. (SCOTT, 1994: 11-29).

Segundo Scott, gênero primeiramente pode ser definido como um "elemento constitutivo das relações sociais fundadas sobre as diferenças percebidas entre os sexos". Por fim, "gênero é um primeiro modo de dar significados às relações de poder". Ou seja, a autora entende que a categoria gênero requer um novo estatuto de história, uma nova demarcação dos métodos, um diálogo constante com outras áreas das ciências humanas. (SCOTT, 1990: 5-22).

Para contestar os paradigmas da história, Joan Scott recomenda a desconstrução como método que permitiria ao historiador verificar como as diferenças sexuais, por exemplo, vistas em seu contexto, são construídas hierarquicamente e dadas como real, como coisas dadas ou como "estando na natureza das coisas".

Neste sentido, o uso do gênero representa a possibilidade de romper com a suposição de uma existência do ser anterior à linguagem, isto é, permite desvincular a análise da formação das identidades sexuais daquela referência usual à diferença biológica macho/fêmea. Assim, a construção das subjetividades binárias podem ser vistas como resultante não dos chamados aspectos naturais do ser humano, mas sim dos confrontos político-sociais cuja significação dimensiona o relacionamento entre as pessoas. O objetivo principal da autora, é verificar como as sociedades constróem representações sobre as diferenças (masculino/feminino) e não se essas representações encontram respaldo ou não na natureza mesma do ser. E mais, na ótica de Scott, a prática discursiva é sempre uma prática de poder, pois tudo o que se torna objeto pelo conhecimento é sempre cultural, na medida em que está sempre mediado pela historicidade do próprio ato de conhecer. (BESSA, 1994).

O trabalho de Joan Scott procura demonstrar que a elaboração e manutenção do esquema binário, mundo dos homens em contraposição ao mundo das mulheres, não se 
restringe a um esquema conceitual que torna legível as experiências humanas de uma determinada sociedade. Consiste, isto sim, em práticas discursivas encontradas nas mais variadas formas e instituições: da fábrica à família, passando pelas ciências sociais e literatura. Essas práticas discursivas forjam verdades vivenciadas nas relações de gênero que cristalizam identidades sexuais, hierarquizam as diferenças e naturalizam o sexo.

Entre as várias críticas formuladas ao gênero como categoria analítica é a de que com o intuito de buscar o fim da discriminação sexual acabou-se elaborando assumindo "uma identidade coletiva de mulheres", baseada no aspecto comum da subordinação social sofrida pelas mulheres.

Algumas das críticas mais veementes a Joan Scott, se direcionam principalmente à ênfase ao estudo da linguagem para analisar a combinação entre os conceitos e as relações já dadas, uma vez que ambos, para a autora, são apenas formalmente separados, mas não de fato na organização social. Para os críticos, Scott estaria colocando os historiadores como reféns da linguagem, transformando a "vida em texto".

A resposta de Scott se direciona no sentido de que esta "ênfase da linguagem" é um desvio do que é central, para ela, na discussão: a polêmica instaurada pelo uso da categoria analítica de gênero.

Por certo, a polêmica maior "conquistada" por Joan Scott consiste no acirrado debate com os historiadores que fazem parte da chamada História Social, em especial com a historiadora Louise Tilly.

Os "desacordos Tilly-Scott", ocorrem principalmente a partir da afirmação de Joan Scott de que a história social pouco ultrapassou os limites da descrição e, além disso, reduziu as ações humanas a uma simples função das forças econômicas, fazendo do gênero apenas um dos seus numerosos subprodutos.

Louise Tilly considera a análise de Scott equivocada pois, para ela, numerosas historiadoras das mulheres que, tendo 
adotado os métodos da história social, levaram seriamente em conta o "problema do ator". Para Tilly, a história descritiva das mulheres, mesmo quando utiliza a abordagem da história social ou econômica, contribuiu amplamente para a revisão dessas abordagens ao utilizar fontes, tais como documentos pessoais ou arquivos públicos que revelam tanto as existências individuais quanto as coletivas. (TILLY, 1994:29-62).

Outra crítica de Louise Tilly se direciona à desconfiança no método da desconstrução proposto por Scott. Em suas palavras:

"a desconstrução é um método que abre novas perspectivas para a nossa compreensão da produção cultural do passado mas minimiza ou rejeita os métodos $e$ as questões decisivas que transformaram profundamente a prática histórica e a história. A ênfase colocada no método e no texto (...) me parece subestimar a ação humana e fazer pender a balança na direção de uma super-estimação da coerção social. (...) Entretanto, por sua vez, ela não se arrisca a negligenciar o ator quando recomenda um método que efetivamente o ignora?". (Grifos Meus).

Ainda para Louise Tilly, Scott preconiza um método que coloca radicalmente em questão não somente as relações de poder, mas também a existência de um mundo real e a possibilidade de descrevê-lo e explicá-lo.

A respeito do desacordo Tilly-Scott, Eleni Varikas salienta que, na verdade, o pano de fundo das diferenças entre as duas historiadoras consistem em preocupações que extrapolam o circuito anglo-americano, fazendo parte mesmo de um debate mundial. Tais preocupações dizem respeito a como lidar com certas questões referentes a: 
"Como fazer para passar das abordagens descritivas para as abordagens "orientadas na direção de uma solução dos problemas"? Como fazer para vincular essas problemáticas àquelas dos outros domínios históricos? Qual é a contribuição da história das mulheres à história geral? E em que ela transformou e, sobretudo, como ela pode transformar o campo histórico no seu conjunto?". (VARIKAS, 1994: 65.).

E, para Varikas, engana-se quem considerar que o melhor encaminhamento para a solução dessas questões seja a escolha entre a história social e a desconstrução, o que resultaria num falso dilema.

Um caminho mais fecundo apontado pela autora, seria realizar um trabalho a partir da diáspora entre a história social e a desconstrução, desestabilizando certezas e reformulando as "grandes questões da história". Um trabalho lento, sem dúvida.

\section{Referências bibliográficas}

ARENDT, Hannah - A Condição Humana - RJ - Forense Universitária - 1991.

BESSA, Karla M. - "O crime de sedução e as relações de gênero" - In: Cadernos Pagu (2) - Campinas - IFCH - UNICAMP 1994.

BRESCIANI, Maria Stela (org.) - Revista Brasileira de História - no. 18 - SP - ANPUH/Marco Zero - 1989/90.

CUNHA, Maria Clementina P. - O Espelho do Mundo - Juquery,

a história de um asilo - RJ - Paz e Terra - 1986.

DEL PRIORE, Mary - A Mulher na História do Brasil - SP Contexto -1989.

GOLDENBERG, Miriam - Toda mulher é meio Leila Diniz RJ - Record - 1996. 
HALL, Catherine - "The Tale of Samuel and Jemima: gender and working class in XIX Century England'"'- In: KAYE, H.\& MCCLELLAND, C. - E. P. Thompson: Critical Perspectives - Philadelphia - Temple U. Press - 1988.

LOBO, Elizabeth S. e PAOLI, Maria Célia - "Notas sobre o movimento no feminino" - In: Desvio - ano I - vol. 1 - nov. 1982.

MARTINS, Ana Paula V. - Possibilidades de Diálogo: classe e gênero - 1996 - (mimeo.).

MURARO, Rose Marie - "Breve Introdução Histórica" - In:

Malleus Maleficarum - RJ- Rosa dos Tempos - 1991.

PENA, Maria Valério J. - Mulheres Trabalhadoras - Presença

Feminina na Construção do Sistema Fabril - RJ - Paz e Terra - 1981.

PERROT, Michele - Os Excluídos - Operários, Mulheres e Prisioneiros - RJ - Paz e Terra - 1988.

- "Práticas da Memória Feminina" - In:

BRESCIANI, Maria Stela (org.) -Revista Brasileira de

História - no. 18 - SP - ANPUH/Marco Zero - 1989/90.

RAGO, Margareth - Do Cabaré ao Lar - A Utopia da Cidade

Disciplinar - 1880/1930 - RJ - Paz e Terra - 1985.

- "A Mulher na Historiografia Brasileira" - In:

SILVA, Zélia L. (org.) - Cultura Histórica em Debate - SP Ed. UNESP - 1994.

REIS, Maria Cândida Delgado - Tessitura de Destinos - Mulher e Educação - 1910/30 -SP - Educ - 1993.

SCOTT, Joan W. - "Gênero: uma categoria útil de análise" - In:

Educação e Realidade - Porto Alegre - v. 6 - no. 2- 1990. - "Prefácio a Gender and Politics of History

" - In: Cadernos Pagu (3) - Campinas - IFCH - UNICAMP

- 1994 - (Trad. de Mariza Corrêa).

SOIHET, Rachel - "Mulheres ousadas e apaixonadas - Uma investigação em processos criminais cariocas (1880-1930) - In: BRESCIANI, Maria Stela (org.) - Revista Brasileira de História - no. 18 - SP - ANPUH/Marco Zero - 1989-90. 
THOMPSON, E. P. - A Miséria da Teoria - Ou um Planetário de Erros - RJ - ZAHAR - 1981.

- "Customs and Common" - In: Studies

in Traditional Popular Culture - N. Y. - The New Press 1993.

TILLY, Louise - "Gênero, história das mulheres e história social" - In: Cadernos Pagu (3) - Campinas - IFCH - UNICAMP 1994 - (Trad. de Ricardo A . Vieira).

VARIKAS, Eleni - "Gênero, experiência e subjetividade: a propósito do desacordo Tilly-Scott" - In: Cadernos Pagu (3) - Campinas - IFCH - UNICAMP - 1994 - (Trad. de Ricardo A . Vieira).

Abstract: This article intends to approach a historiographic balance about the feminine theme, specially some impressives historiographics sources: marxism, social history and gender studies, during the 70's until 90's, in Brazil.

Keywords: Historiography, Women, Gender. 